\title{
A Health crisis is a social crisis
}

\section{Michael Marmot \\ Institute of Health Equity \\ Department of Epidemiology and Public Health \\ UCL}

\section{m.marmot@ucl.ac.uk \\ @MichaelMarmot}

Something is going badly wrong with society in the UK and the USA. Brexit and Trump? Of course Brexit and Trump, but they are more the result of what has gone wrong rather than the cause - although they are wreaking their own havoc. A simple summary measure of the success of a society is its health. Life expectancy has declined in the US, three years in a row(1) and in the UK it has stalled since around 2011. (2)

When attention was first drawn to the slowing of life expectancy gains in $\operatorname{England}(3,4)$, concerns were raised that it was not "real" - perhaps a severe winter was causing a short term fluctuation. That speculation is given the lie by the latest publication from ONS that shows life expectancy has stopped increasing in England and marginally declined among men and women in Scotland, and in Wales, and among men in Northern Ireland between 2015 and 2017.(2) The life assurance industry is in no doubt that the slow down is real they are making unanticipated profits - and the Institute of Actuaries has downgraded its core projection of cohort life expectancy at age 65(5).

As a further indicator of societal ills, health inequalities are increasing both in the UK and USA. In women, particularly, life expectancy has declined in the most deprived areas of England - the more deprived the area, the steeper the decline(6). Inequalities in health derive from inequalities in society(7).

Initially, the slowing of life expectancy in the UK appeared to come from a rise in mortality in older men and women. The US experience, by contrast, was marked by a rise in mortality in middle-aged non-Hispanic white men and women. The big contributors were deaths from accidental poisonings, opioids, suicide, and alcohol. In case there was any doubt that this rise in mortality reflected important social trends, Case and Deaton labelled these as 'deaths of despair'.(8) Mortality has also been rising among American Indians and Alaskan Natives and is now rising in African Americans - all of whom have always had higher rates than among whites.(9)

There are now signs that the UK may be heading in the US direction. There is a rise in deaths of despair, albeit on a smaller scale than in the US. These trends combined have led to a rise in mortality in young adults and in middle-age.(10). The UK, as do other rich countries, rejoices in an infant mortality of three to four deaths per thousand live births. Even here, there is a worrying trend, a stable rate in the most affluent $10 \%$ of neighbourhoods between 2015 and 2016, and an increase to nearly six per thousand deaths in the most deprived.(11) 
It is of course important not only to document these trends but to understand their causes and to do something about them. In the US, deaths of despair follow the social gradient the fewer the years of education the higher the rate. Case and Deaton speculate that cumulative disadvantage takes its toll on less educated people, with deteriorating job prospects, stalling incomes, social isolation and relationship breakdown all contributing.

In the UK, the fact that the break in the long-term rise in life expectancy in the UK began in 2011, and has been accompanied by an increase in health inequalities, cannot but lead us to ask the question of whether the government elected in 2010, with its flagship policies of austerity, made a difference for the worse. It is difficult to answer such questions with precision. Especially so, because health inequalities do indeed a rise from a cumulation of disadvantage across the life course. Barr and colleagues entered this tricky domain(12). They pointed out that the Labour government of 1997 to 2010 had a strategy to reduce health inequalities. To ask whether the strategy worked, they examined the gap in life expectancy between the poorest $20 \%$ of areas in England and the rest. Before the strategy inequalities in life expectancy were increasing; during the strategy inequalities diminished; when a new government came in with different policies, inequalities again widened. These researchers reached similar conclusions about infant mortality.(13) These results chime with analyses from the US of the long-term downward trend in infant mortality from 1965 to 2010. When a Republican was in the White House the downward trend slowed a little; when it was a Democrat, the trend was a little faster(14).

A failure of health to continue to improve, and increases in health inequalities, are of concern to all of us who care about health. It should also be a concern to anyone who cares about the society in which we live. Increases in inequalities of social conditions, worsening child poverty, cuts to services and, indeed, voting for Brexit or Trump, will all make society worse. Health inequalities are telling us something fundamental about our society.

1. National Center for Health Statistics. Health, United States, 2017: With special feature on mortality. Hyattsville, MD: National Center for Health Statistics.; 2018.

2. ONS. Quarterly mortality report, England: October to December 2018 and year-end review. UK: Office for National Statistics; 2019.

3. Hiam L, Dorling, D., Harrison, D., McKee, M.,. What caused the spike in mortality in England and Wales in January

2015? J R Soc Med. 2017;110:131-7.

4. Institute of HealthEquity Marmot Indicators Briefing. 2017. 2017.

5. Institute of Actuaries. CMI_2018: the latest version of the CMI Mortality Projections

Model March 2019. https://wwwactuariesorguk/learn-and-develop/continuous-mortalityinvestigation/cmi-working-papers/mortality-projections/cmi-working-paper-119. 2019.

6. ONS. Health state life expectancies by national deprivation deciles, England and Wales: 2015 to 2017. 2018.

7. Marmot M. The Health Gap. London: Bloomsbury; 2015.

8. $\quad$ Case A, Deaton A Mortality and Morbidity in the 21st Century.; 2017.

9. Woolf S H CDA, Buchanich J M, Bobby K J, Zimmerman E B, Blackburn S M et al. Changes in midlife death rates across racial and ethnic groups in the United States: systematic analysis of vital statistics. BMJ. 2018;362:k3096. 
10. Public Health England. A review of recent trends in mortality in England.

https://www.gov.uk/government/publications/recent-trends-in-mortality-in-englandreview-and-data-packs; 2018.

11. ONS. Child mortality statistics in England and Wales: 2016. 2018.

12. Barr B, Higgerson, J., Whitehead, M. Investigating the impact of the English health inequality strategy: time trend analysis. BMJ. 2017;358:j3310.

13. Robinson T ea. J Epidemiol Community Health. 2019.

14. Rodriguez J M JBJ, Geronimus A T. US infant mortality and the President's party. International Journal of Epidemiology. 2014;43:818-26. 